\title{
Synthesis and properties of quinazoline-based versatile exciplex-forming compounds
}

\author{
Rasa Keruckiene, Simona Vekteryte, Ervinas Urbonas, Matas Guzauskas, \\ Eigirdas Skuodis, Dmytro Volyniuk and Juozas V. Grazulevicius*
}

\author{
Full Research Paper \\ Address: \\ Department of Polymer Chemistry and Technology, Kaunas University \\ of Technology, K. Baršausko g. 59, Kaunas 51423, Lithuania

\section{Email:} \\ Juozas V. Grazulevicius* - juozas.grazulevicius@ktu.It \\ * Corresponding author \\ Keywords: \\ carbazole; dimethyldihydroacridine; exciplex; phenothiazine; \\ quinazoline
}

\author{
Beilstein J. Org. Chem. 2020, 16, 1142-1153. \\ doi:10.3762/bjoc.16.101 \\ Received: 16 March 2020 \\ Accepted: 12 May 2020 \\ Published: 28 May 2020 \\ Associate Editor: P. J. Skabara \\ (C) 2020 Keruckiene et al.; licensee Beilstein-Institut. \\ License and terms: see end of document.
}

\begin{abstract}
Three compounds, bearing a quinazoline unit as the acceptor core and carbazole, dimethyldihydroacridine, or phenothiazine donor moieties, were designed and synthesized in two steps including a facile copper-catalyzed cyclization and a nucleophilic aromatic substitution reaction. The photophysical properties of the compounds, based on theoretical calculations and experimental measurements, as well as the electrochemical and thermal properties, are discussed. The synthesized compounds form glasses with glasstransition temperatures ranging from $116^{\circ} \mathrm{C}$ to $123{ }^{\circ} \mathrm{C}$. The ionization potentials estimated by cyclic voltammetry of the derivatives were in the range of 5.22-5.87 eV. The 3,6-di-tert-butylcarbazole-substituted quinazoline-based compound forms a sky-blue emitting exciplex in solid mixture with the acceptor 2,4,6-tris[3-(diphenylphosphinyl)phenyl]-1,3,5-triazine as well as an orange emitting exciplex with the donor 4,4',4"-tris[3-methylphenyl(phenyl)amino]triphenylamine. A white OLED based on these versatile exciplex systems with a relatively high maximum brightness of $3030 \mathrm{~cd} / \mathrm{m}^{2}$ and an external quantum efficiency of $0.5 \%$ was fabricated.
\end{abstract}

\section{Introduction}

Organic luminescent materials are extensively used in a wide range of optoelectronic devices. For the design of compounds, potentially exhibiting properties such as bipolar charge transport, delayed fluorescence or aggregation-induced emission enhancement (AIEE), a useful strategy is to employ both donor and acceptor moieties in a single molecular structure [1-4].
Quinazoline is a planar aromatic heterocyclic compound with the fused bicyclic structure consisting of benzene and pyrimidine rings. Quinazoline derivatives were investigated and used in medicinal applications, such as monitoring of specific biological activities and as antimalarial and anticancer agents $[5,6]$. However, electroactive properties of derivatives of this acceptor 
have been scarcely reported. Quinazoline-based compounds were used as hosts for red phosphorescent OLEDs with an external quantum efficiency (EQE) of 19.2\% [7]. Two blue emitters based on fluorene-bridged quinazoline and quinoxaline derivatives were used in the active layers of OLEDs with EQEs of $1.58 \%$ and $1.30 \%$, suggesting that the self-aggregation of emitters had a considerable effect on the photoluminescent and electroluminescent properties [8]. A quinazoline-based emitter exhibiting thermally activated delayed fluorescence (TADF) was also reported [6] and green to yellow TADF OLEDs were fabricated with EQEs from 17.6 to $20.5 \%$. The multicolor emission of a quinazoline-carbazole compound was employed in white OLEDs. White photoluminescence and electroluminescence based on blue emissive quinazoline derivatives obtained through controlled acid protonation were employed in a single-layered white OLED with EQEs of $1.4 \%$ and $3 \%$ [9]. These reports proved that by using an asymmetric quinazoline acceptor, highly efficient TADF materials for OLEDs could be obtained with easy modulation of the electroluminescent properties. Recently, the first examples of versatile exciplex-forming materials which can form two different types of exciplexes, donor-acceptor/donor and acceptor/ donor-acceptor, were reported for simplified non-doped white OLEDs [10]. However, the maximum external quantum efficiencies (EQEs) of such white exciplex-based OLEDs did not exceed $3.2 \%$. It is predictable, that investigation of such versa- tile exciplex-forming materials will allow to develop highly efficient exciplex-based OLEDs.

With the above mentioned aim, herein we report on the synthesis and properties of electroactive compounds bearing a quinazoline moiety as an acceptor and the widely used carbazole, phenothiazine and dimethyldihydroacridine species as donors [11-13].

\section{Results and Discussion Synthesis and thermal properties}

Aromatic rigid moieties were selected in the build-up of the new electroactive compounds. The commonly used carbazole, phenothiazine, and dimethyldihydroacridine donor units and the scarcely used quinazoline unit as the electron acceptor were chosen for the design of the compounds (Scheme 1).

A facile and reliable one-pot three-component method was used for the quinazoline formation by refluxing 2-aminobenzophenone, difluorobenzaldehyde, ammonium acetate, and $\mathrm{CuCl}_{2}$ in ethanol. The synthetic method using a cheap catalyst, easy workup, and the high yield (78\%) of quinazoline Q1 makes the compound a promising candidate as an electron acceptor in donor-acceptor systems [14]. The target compounds were obtained by nucleophilic substitution reaction of the intermediate quinazoline derivative $\mathbf{Q 1}$ with the corresponding donor com-<smiles>[2H]c1ccc(-c2nc(-c3ccccc3)c3ccccc3n2)cc1</smiles><smiles>CC(C)(C)c1ccc2c(c1)c1cc(C(C)(C)C)ccc1n2-c1cc(-c2nc(-c3ccccc3)c3ccccc3n2)cc(-n2c3ccc(C(C)(C)C)cc3c3cc(C(C)(C)C)ccc32)c1</smiles><smiles>[Z]C1(C)c2cc(C(C)(C)C)ccc2N(c2cc(-c3nc(-c4ccccc4)c4ccccc4n3)cc(N3c4ccc(C(C)(C)C)cc4C(C)(C)c4cc(C(C)(C)C)ccc43)c2)c2ccc(C(C)(C)C)cc21</smiles><smiles>CC(C)(C)c1ccc2c(c1)Sc1cc(C(C)(C)C)ccc1N2c1cc(-c2nc(-c3ccccc3)c3ccccc3n2)cc(N2c3ccc(C(C)(C)C)cc3Sc3cc(C(C)(C)C)ccc32)c1</smiles>

3

Scheme 1: Synthesis of quinazoline derivatives 1-3. Conditions: i) ammonium acetate, copper(II) chloride, isopropanol, reflux, $24 \mathrm{~h}$; ii) donor moiety (D), NaH, DMF, reflux, $24 \mathrm{~h}$. 
pounds. The chemical structures were characterized by ${ }^{1} \mathrm{H}$ NMR, ${ }^{13} \mathrm{C}$ NMR, ATRIR spectroscopy and mass spectrometry.

All compounds 1-3 were obtained as crystalline substances. The thermal characteristics were determined by differential scanning calorimetry (DSC) and thermogravimetric analysis (TGA). During the first DSC heating scan (Figure 1a-c), melting signals of compounds $\mathbf{1}-\mathbf{3}$ were detected in the range from $181{ }^{\circ} \mathrm{C}$ to $243{ }^{\circ} \mathrm{C}$. Compounds 2 and $\mathbf{3}$, bearing dimethyldihydroacridine and phenothiazine moieties formed molecular glasses. The glass transitions were detected during the cooling and the second heating scans at $123{ }^{\circ} \mathrm{C}$ and $116^{\circ} \mathrm{C}$, respectively. No glass transition was detected for compound $\mathbf{1}$, that only showed a crystallization signal $\left(T_{\mathrm{CR}}=138^{\circ} \mathrm{C}\right)$ during the cooling scan. The $10 \%$ weight-loss temperature $\left(T_{\mathrm{D}-10 \%}\right)$ of the quinazoline-based compounds decreased in the order of $\mathbf{3}$ $\left(409{ }^{\circ} \mathrm{C}\right)>\mathbf{2}\left(345^{\circ} \mathrm{C}\right)>\mathbf{1}\left(247^{\circ} \mathrm{C}\right)$. For compounds $\mathbf{1}$ and $\mathbf{2}$ a complete weight loss was observed in the TGA experiments. This observation showed, that the weight loss of these compounds apparently was due to sublimation. The carbon residue of compound 3 was attributed to the tendency of the phenothiazine moiety to decompose rather than to sublimate, as it has been observed for similar phenothiazine-based compounds [15].

\section{Theoretical calculations and electrochemical properties}

DFT calculations were employed to gain insight into the structure-property relationships of the quinazoline-based derivatives 1-3. The compounds have phenyl spacers between the donor and acceptor units (Figure 2). Therefore, the dihedral angle values were estimated between the bonded aromatic unit and the respective substituents. All compounds showed large twisting angles that indicated HOMO and LUMO separation and a controlled conjugation distance. In the optimized groundstate geometries, the acceptor and the phenyl units are plane, whereas the dihedral angles between the donor moieties and phenyl unit varied and were found to be $126^{\circ}$ for $1,90^{\circ}$ for 2 , and $118^{\circ}$ for 3 .

The twisted configurations of compounds $\mathbf{2}$ and $\mathbf{3}$ fully separated the HOMO and LUMO orbitals. The oscillator strengths

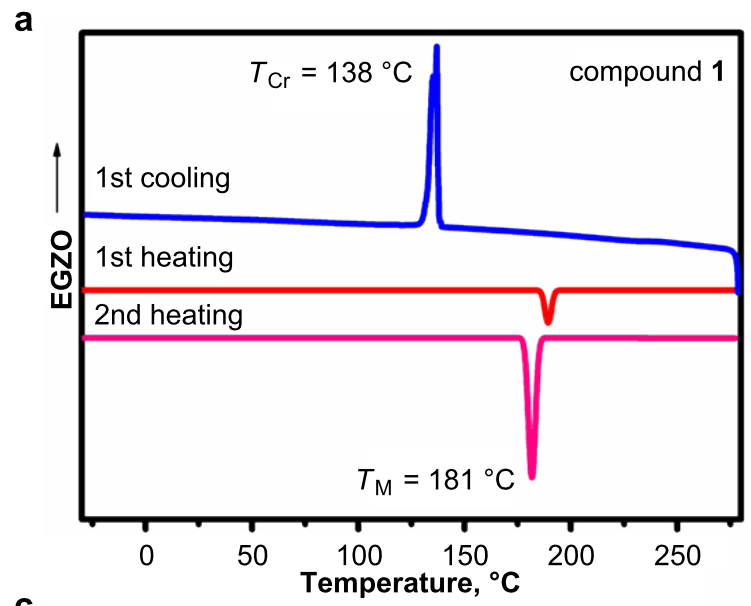

b

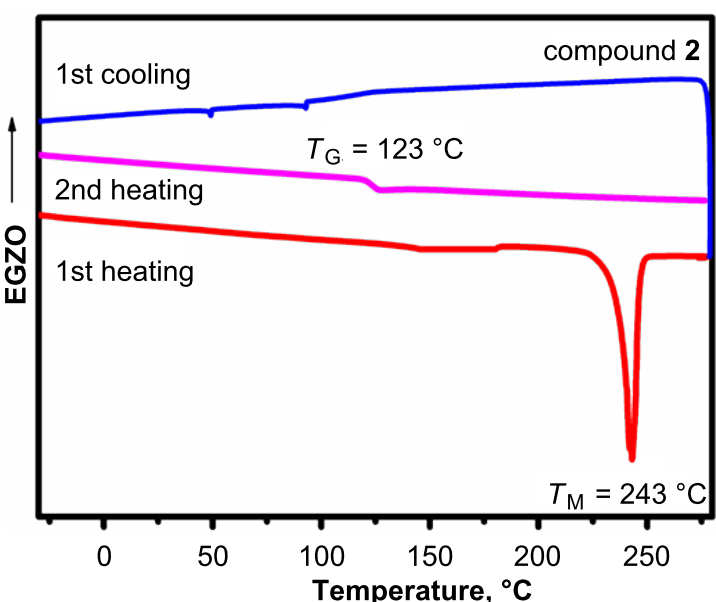

c

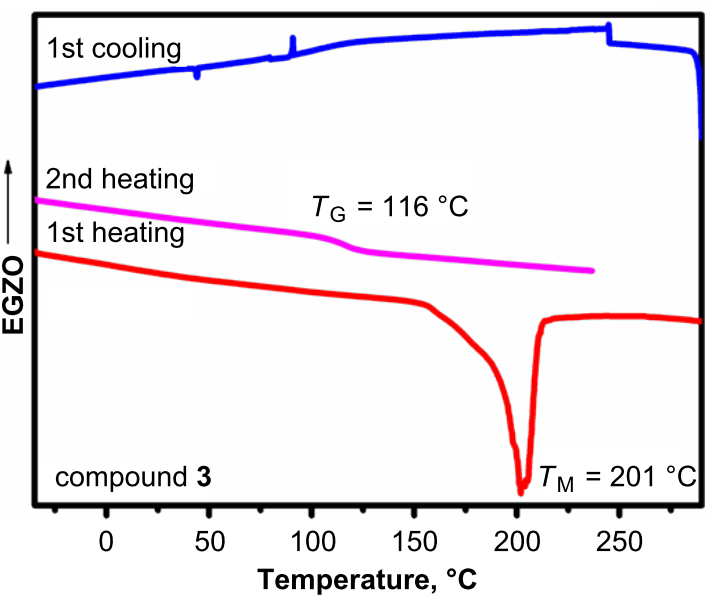

d

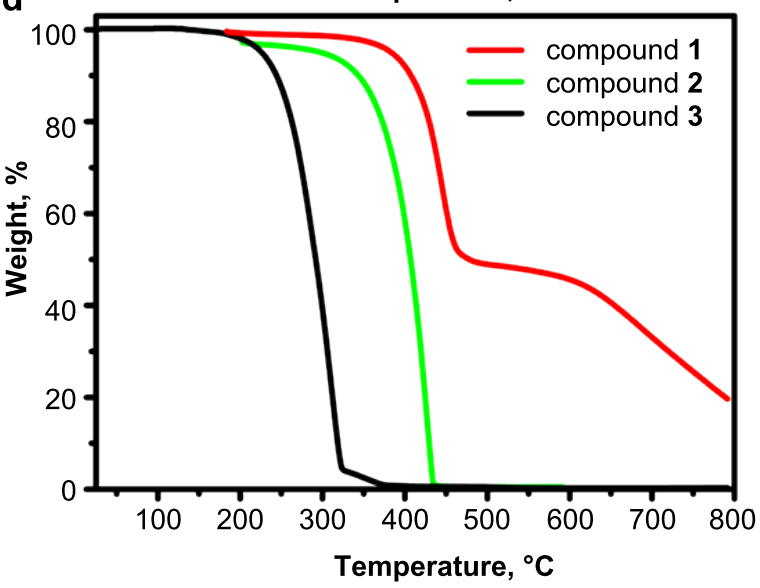

Figure 1: DSC (a, b, c) and TGA (d) curves of compounds 1-3. Scan rates were $20^{\circ} \mathrm{C} / \mathrm{min}(\mathrm{TGA})$ and $10^{\circ} \mathrm{C} / \mathrm{min}(\mathrm{DSC})$. 


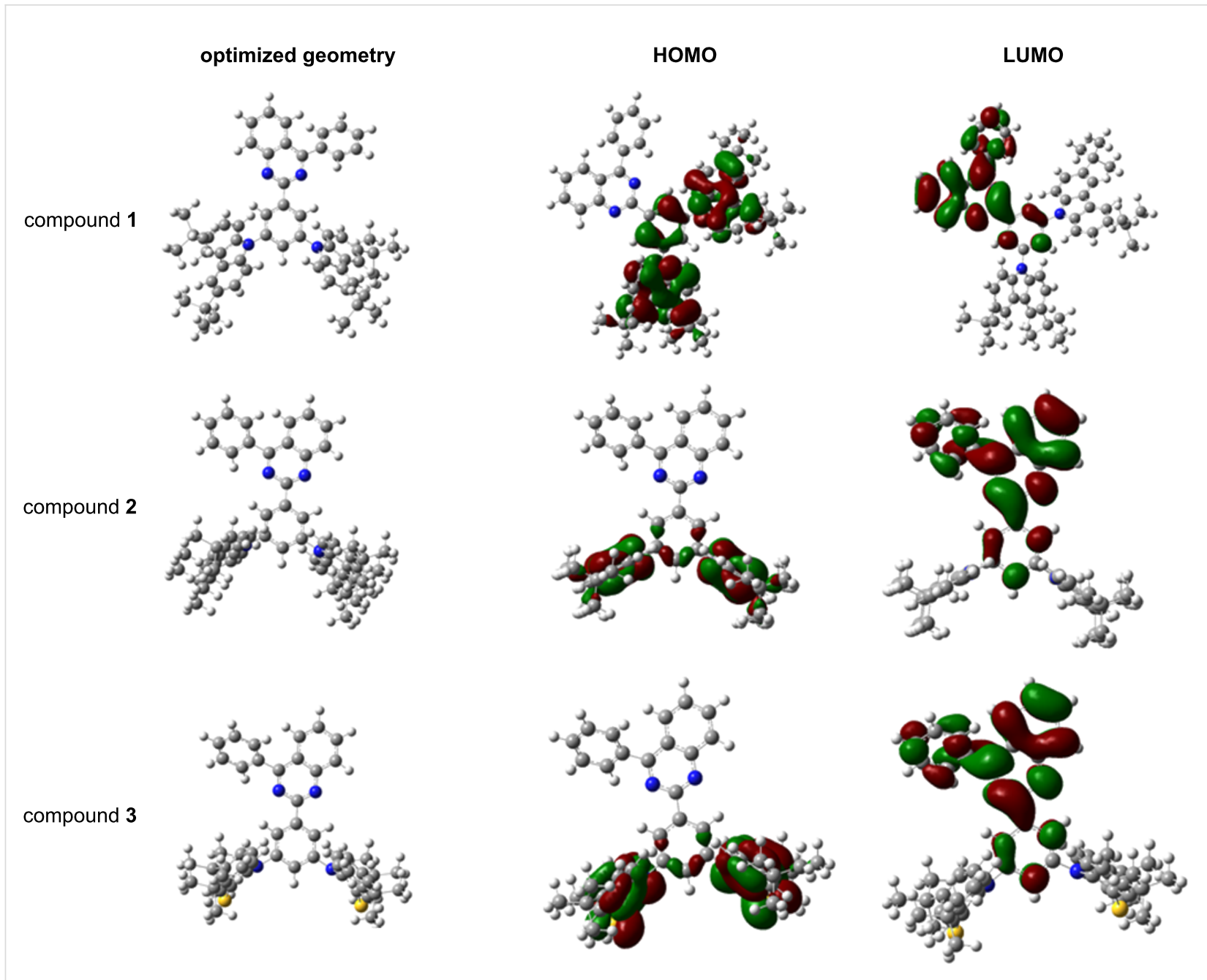

Figure 2: Frontier-orbital distributions and optimized geometries at the ground state of quinazoline-based compounds 1-3, calculated at the B3LYP/6$31 \mathrm{G}(\mathrm{d}, \mathrm{p})$ level of theory.

were 0.0 indicating that it is spin-forbidden due to a quasi-orthogonal geometry of the donor part on the acceptor core, and the charge-transfer (CT) character [16].

On the other hand, not adapting the vertical dihedral angle enabled a slight HOMO and LUMO overlap in the geometry of compound 1. This resulted in a higher oscillator strength of 0.0109. As shown in Figure 2, the LUMOs were located on the central electron-accepting quinazoline core and the phenyl unit, whereas the HOMOs were mainly localized on the electron-donating peripheral substituents.

The HOMO energy values (Table 1) showed dependence on the donating characteristics of the substituents of the quinazoline derivatives 1-3, whereas the LUMO energies were close and characteristic of the quinazoline unit. The electron-donating characteristics were investigated experimentally by cyclic vol- tammetry (CV). All three compounds showed reversible oxidation (Figure 3 ) and the data are summarized in Table 1.

The ionization potential $\left(\mathrm{IP}_{\mathrm{CV}}\right)$ and electron affinity $\left(\mathrm{EA}_{\mathrm{CV}}\right)$ values were estimated accordingly from the oxidation and reduction onset potentials against ferrocene $\left(E_{\mathrm{OX}} / E_{\text {red,onset vs Fc }}\right)$. The $\mathrm{IP}_{\mathrm{CV}}$ values demonstrated the similar and collaborative electron-donating effect of the carbazole, phenothiazine, and 2,7-di-tert-butyl-9,9-dimethylacridine donor moieties on the electron-releasing energy.

The phenothiazine-substituted quinazoline compound 3 required the lowest energy for electron release compared to the other compounds studied. The electron affinity values were comparable as they characterize the electron-withdrawing abilities of the quinazoline moiety present in all compounds. The energy bandgap values estimated from CV measurements indi- 
Table 1: Electrochemical characteristics.

\begin{tabular}{|c|c|c|c|c|c|c|c|}
\hline Compound & $E_{\text {red. vs } \mathrm{Fc}^{\mathrm{a}}}, \mathrm{V}$ & 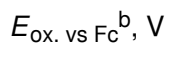 & $\mathrm{IP}_{\mathrm{CV}}{ }^{\mathrm{c}}, \mathrm{eV}$ & $E_{C V}{ }^{d}, e V$ & $E_{\mathrm{g}} \mathrm{CVe}, \mathrm{eV}$ & $\mathrm{HOMO}^{f}, \mathrm{eV}$ & LUMO', eV $^{\circ}$ \\
\hline 1 & -1.70 & 0.77 & 5.87 & 3.39 & 2.48 & 5.13 & 2.10 \\
\hline 2 & -1.59 & 0.31 & 5.41 & 3.51 & 1.90 & 4.64 & 2.10 \\
\hline 3 & -1.59 & 0.12 & 5.22 & 3.51 & 1.71 & 4.74 & 2.18 \\
\hline
\end{tabular}

aOnset reduction potential of the sample vs onset oxidation potential of ferrocene; bonset oxidation potential of the sample vs onset oxidation potential of ferrocene; Cionization potential, $\mathrm{IP}_{\mathrm{CV}}=E$ onset oxidation vs $\mathrm{FC}+5.1 \mathrm{eV}[17,18]$; ${ }^{\mathrm{d}}$ electron affinity, $\mathrm{EA} \mathrm{CV}=5.1 \mathrm{eV}-E_{\mathrm{red}} \mathrm{vs} \mathrm{FC}_{\mathrm{C}}$, electrochemical bandgap $E_{\mathrm{g}} \mathrm{CV}=\mathrm{IP}_{\mathrm{CV}}-\mathrm{EA}_{\mathrm{CV}}$; ${ }^{\mathrm{f}}$ theoretically calculated HOMO energy; 9 theoretically calculated LUMO energy.

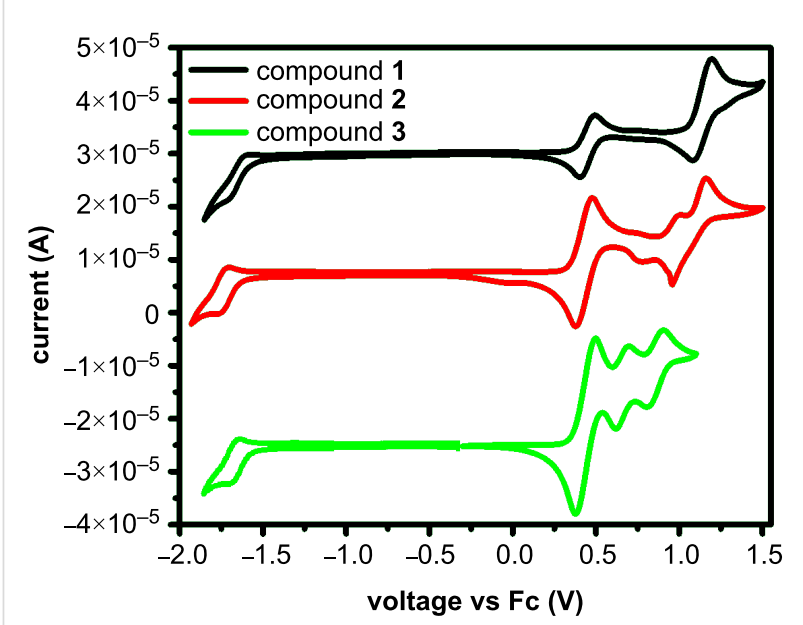

Figure 3: Cyclic voltammograms of quinazoline-based compounds 1-3.

cated a more extended $\pi$-electron conjugation system for compound $\mathbf{1}$ compared to compounds $\mathbf{2}$ and $\mathbf{3}$. These results correlated well with the results of theoretical calculations which revealed that the HOMO and LUMO orbitals of the carbazolesubstituted quinazoline compound $\mathbf{1}$ overlap.

\section{Photophysical and electronic properties}

Figure 4 shows the theoretical UV spectra and experimental absorption spectra of dilute THF solutions of compounds $\mathbf{1 - 3}$. The theoretical UV-vis spectra of the derivatives had single absorption bands. The band at ca. $310 \mathrm{~nm}$ was characterized by a combination of various transitions towards several excited states. The theoretical UV spectrum of derivative $\mathbf{1}$ had a shoulder at $390 \mathrm{~nm}$. In general, the experimental UV spectra of the derivatives 1-3 were consistent with the theoretical ones. The UV spectra of compounds $\mathbf{1}, \mathbf{2}$, and $\mathbf{3}$ had lowest energy bands (LEB) at 350, 280, and $325 \mathrm{~nm}$, which were the main characteristics of the donor moieties in the structures, i.e., the carbazole, dimethyldihydroacridine, and phenothiazine moieties, respectively [19]. Additionally, a weak absorption band (shoulder) at ca. $348 \mathrm{~nm}$ was detected for compound $\mathbf{2}$, evidencing an intramolecular charge transfer (ICT) between the phenothiazine and quinazoline units. The energy band gap values determined from the edges of the experimental UV spectra of the derivatives 1-3 correlated with electrochemically estimated ones and with the ionization potential values discussed above. The photophysical characteristics determined from the UV-vis absorption and photoluminescence spectra are collected in Table 2.

The emission spectra of diluted toluene solutions of derivatives $\mathbf{1}$ and $\mathbf{2}$ displayed broad Gaussian forms, whereas the emission spectrum of compound $\mathbf{3}$ was narrow and slightly vibrational (Figure 5). The strongly red-shifted fluorescence bands (ca. $107 \mathrm{~nm}$ for 1 and $156 \mathrm{~nm}$ for 2) with respect to the LEB of absorption, were attributed to charge-transfer (CT) transitions [20]. The PLQY quantum yields of the dilute solutions did not exceed $2 \%$.

Table 2: Photophysical properties of compound 1-3.

\begin{tabular}{|c|c|c|c|c|}
\hline Compound & $\lambda_{\mathrm{abs}}{ }^{\mathrm{a}}, \mathrm{nm}$ & $\lambda_{\mathrm{PL}}{ }^{\mathrm{b}}, \mathrm{nm}$ & PLQY, \% & $E_{\mathrm{g}}{ }^{\text {opt c }}, \mathrm{eV}$ \\
\hline medium & THF & \multicolumn{3}{|c|}{ toluene solution (thin film) } \\
\hline 1 & $301,331,345$ & $453(370)$ & $1(6)$ & 3.47 \\
\hline 2 & 280,348 & $506(521)$ & $2(5)$ & 3.39 \\
\hline 3 & 325 & $450(450)$ & $1(2)$ & 3.29 \\
\hline
\end{tabular}

${ }^{a} \lambda_{\text {abs }}$ are wavelengths of absorption maxima; ${ }^{b} \lambda_{P L}$ are wavelengths of emission maxima; ${ }^{c} E_{g}$ opt is optical band gap estimated as $1240 / \lambda_{a b s}$ onset where $\lambda_{\mathrm{abs}}$ onset is the wavelength of the onset of absorption. 
a

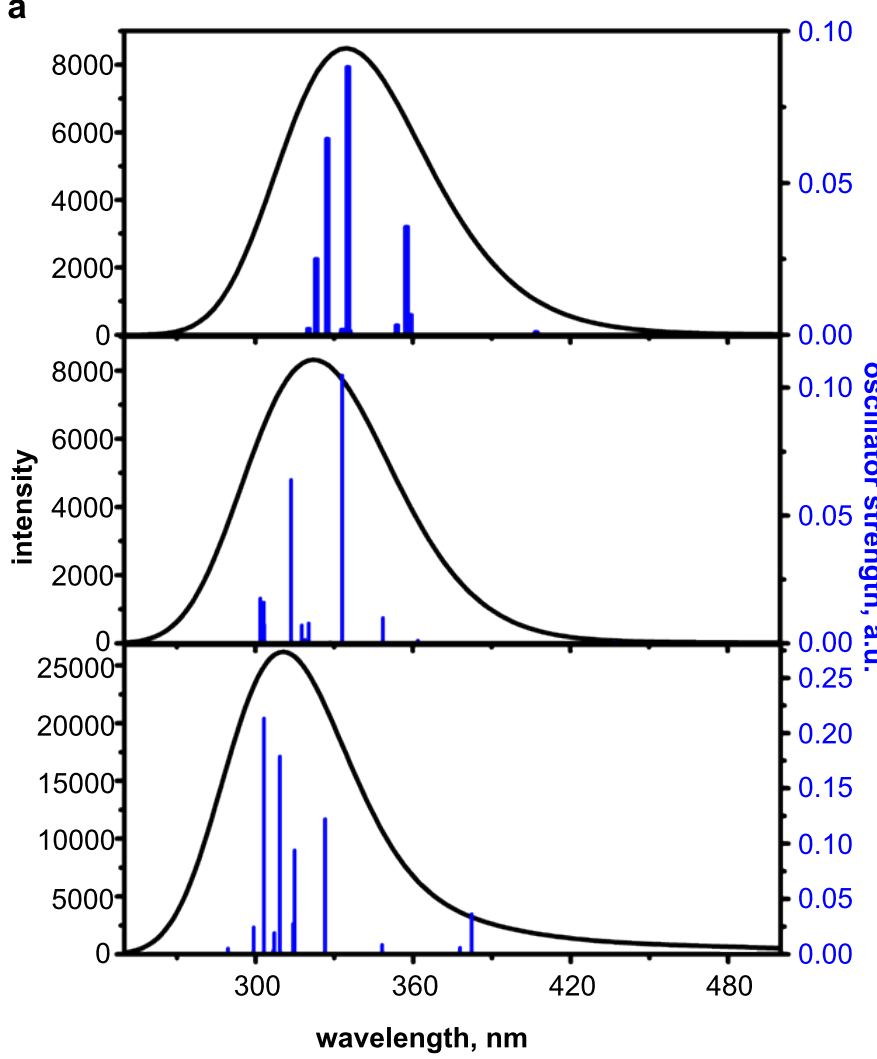

b

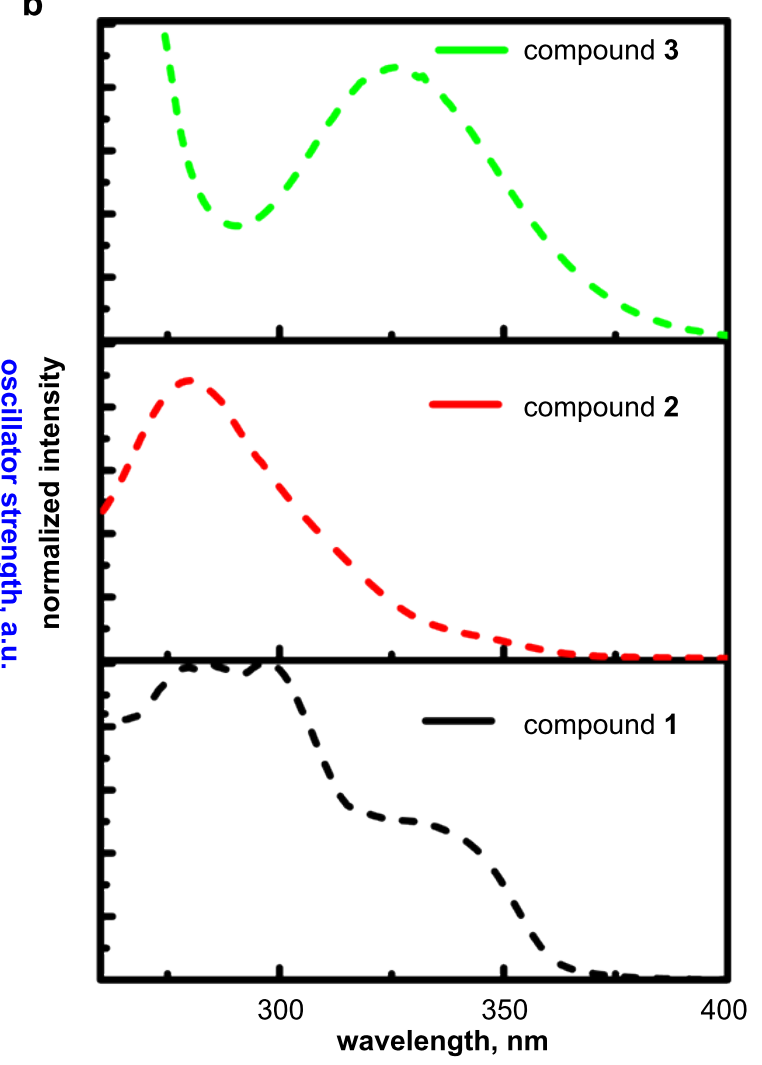

Figure 4: UV-vis absorption spectra of compounds 1-3. a) Theoretical and b) experimental spectra of compounds 1-3 in THF solution.

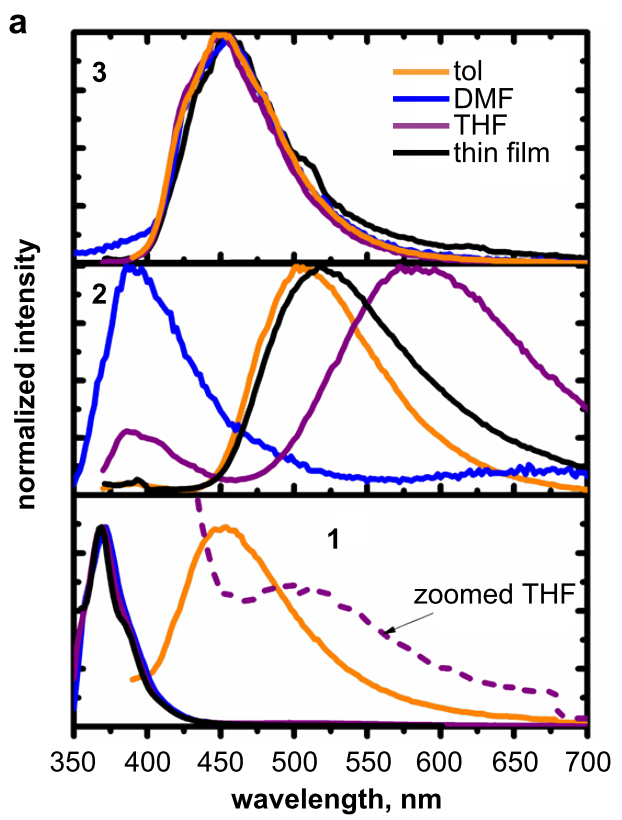

b

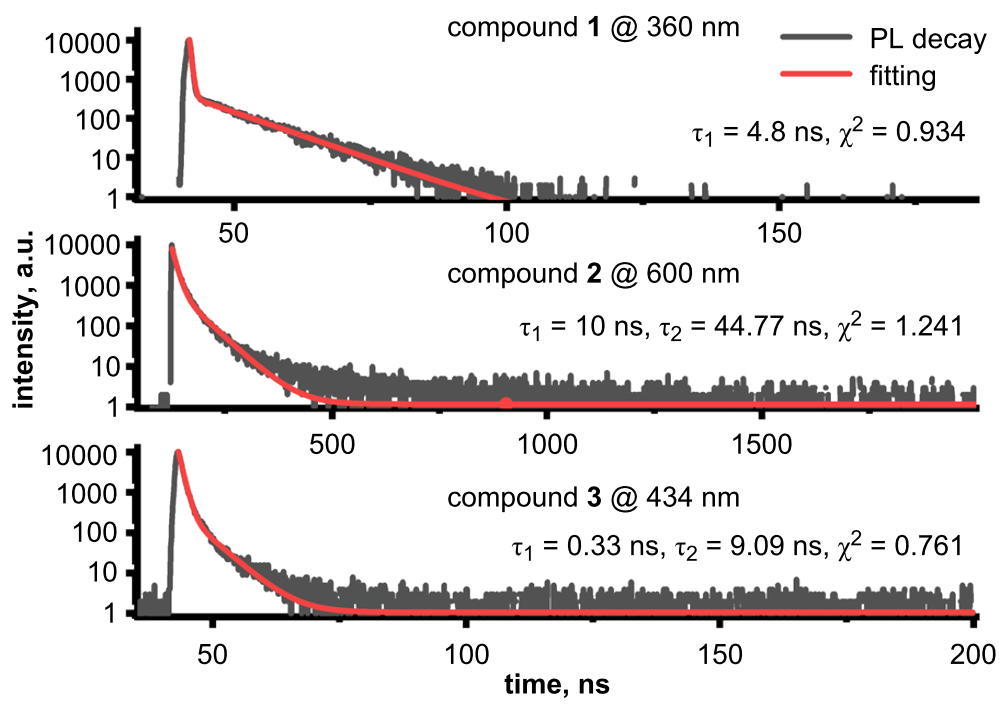

Figure 5: Fluorescence spectra (a) of dilute solutions and thin films of compounds $1-3\left(\lambda_{\text {exc }}=350 \mathrm{~nm}\right.$ and PL decay curves (b) of thin films of derivatives 1-3 recorded at different emission wavelengths. 
The dependence of the emission wavelengths of the derivatives on the solvent polarity was also tested. Figure 5 shows the emission spectra of the compounds dissolved in three solvents with increasing polarities, i.e., toluene (0.099), tetrahydrofuran (0.207) and dimethylformamide (0.4) (values in parentheses are the solvent polarities relative to water) [21]. The PL spectra of the solutions of compound $\mathbf{3}$ appeared to be solvent-polarity independent as only the structured emission band of the locally excited $\left({ }^{1} \mathrm{LE}\right)$ state at $450 \mathrm{~nm}$ was observed. In contrast, compound 2 bearing dimethyldihydroacridine as the donor moiety, possessed the most sensitive ${ }^{1} \mathrm{CT}$. A positive solvatochromism was observed resulting in bathochromic shifts of the PL spectra in the solvents with increasing polarizability indexes. Interestingly, the intensive emission band of the locally excited $\left({ }^{1} \mathrm{LE}\right)$ state at $400 \mathrm{~nm}$ and a weak ${ }^{1} \mathrm{CT}$ state at ca. $677 \mathrm{~nm}$ were also present in the PL spectrum of the solution of compound $\mathbf{2}$ in the polar solvent DMF. The PL spectra of the solutions of compound $\mathbf{1}$ in polar solvents were dominated by the band of the ${ }^{1} \mathrm{LE}$ transition at $375 \mathrm{~nm}$. A ${ }^{1} \mathrm{CT}$ state could be formed for compound 1 as evidenced by the PL spectrum of its solution in lowpolarity toluene. A weak low energy ${ }^{1} \mathrm{CT}$ band was also observed for the solution in THF with moderate polarity (see the zoomed spectrum of THF solution of compound 1, Figure 5a)

To assist in the analysis of the spectra, natural transition orbitals (NTO) for the S1 state were generated. Figure 6 shows the pairs of electron-hole NTOs for the relaxed S1 excited-state geometry. These orbitals indicate which changes in electronic density occur upon relaxation. For all three compounds, the transition took place between orbitals delocalized over both donor fragments and the quinazoline moiety indicating a charge transfer in vacuum. Considering the experimental data, it could be presumed that this ${ }^{1} \mathrm{CT}$ state is very sensitive and easily quenched in polar solvents as it competes with a ${ }^{1} \mathrm{LE}$ transition originating from the donor moieties.

The emission spectra of solid samples of compounds $\mathbf{2}$ and $\mathbf{3}$ were broad and had ${ }^{1} \mathrm{CT}$ character (Figure 5). Meanwhile, PL of the solid sample of compound $\mathbf{1}$ originated from the ${ }^{1} \mathrm{LE}$ state. The PL spectrum of the solid sample was identical to that of the solution in a polar solvent, apparently because of the high polarity of compound $\mathbf{1}$. Furthermore, the emission of the solid sample was more efficient than that of the solution, with a PLQY of up to $6 \%$. In order to determine the origin of the emission, PL decay curves of the solid samples of compounds 1-3 were recorded (Figure 5b). The PL decay curve of the solid sample of the carbazole-containing compound (1) was adequately described by a single-exponential function with a lifetime of $4.8 \mathrm{~ns}$ (prompt fluorescence). The PL decay curves of compounds $\mathbf{2}$ and $\mathbf{3}$ were found to be double exponential with the lifetimes of both components in the ns range. Thus, compounds $\mathbf{2}$ and $\mathbf{3}$ were characterized by prompt fluorescence

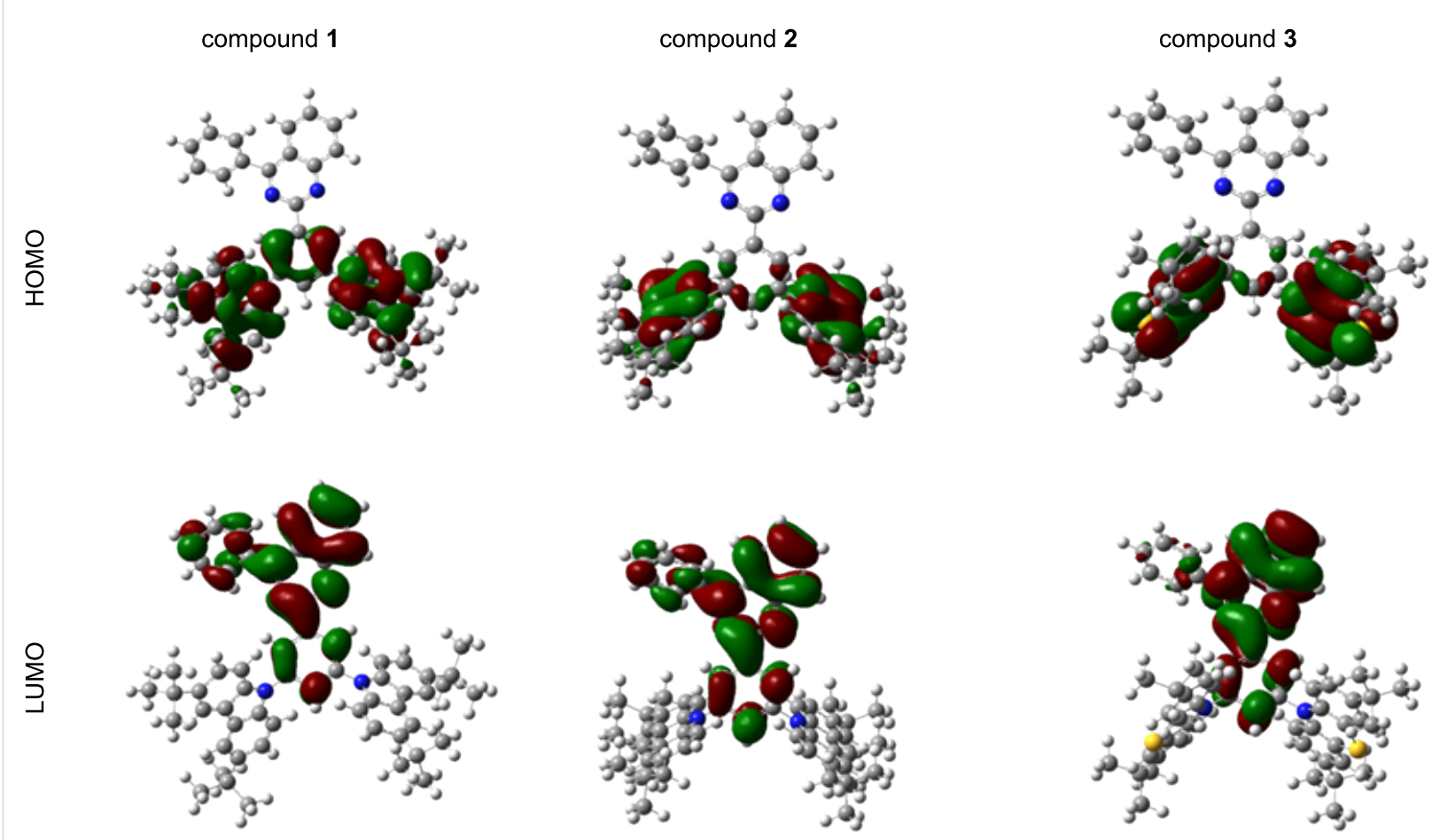

Figure 6: Electron and hole NTOs of compounds 1-3 in the S1 excited state (vacuum). 
and no delayed fluorescence was observed. The double-exponential decays were apparently related to the spectral diffusion (exciton migration and localization at lower energy states) which is usually detected for materials exhibiting low-intensity emissions [22,23].

\section{Exciplex-forming properties}

Since compound $\mathbf{1}$ was characterized by the most blue-shifted fluorescence in the solid-state and a high first triplet energy level of $2.97 \mathrm{eV}$ (Figure 5a and Figure 7a), this compound was regarded as a promising candidate for blue exciplex formation a

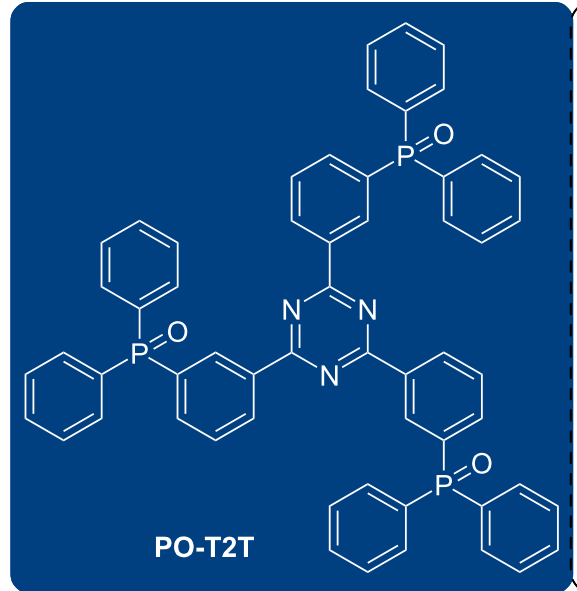

b

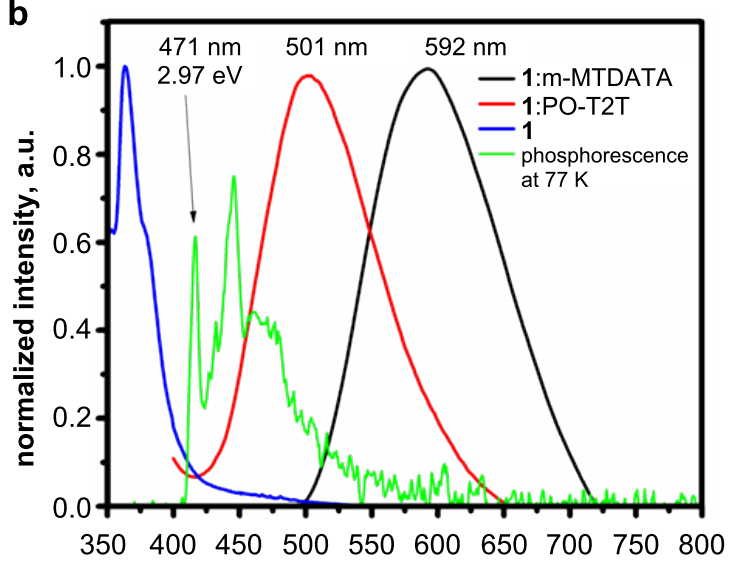

wavelength, $\mathrm{nm}$

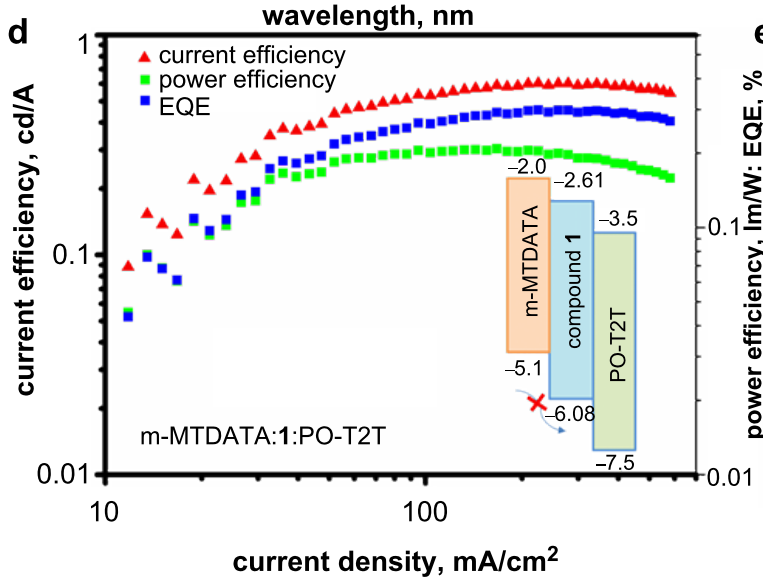

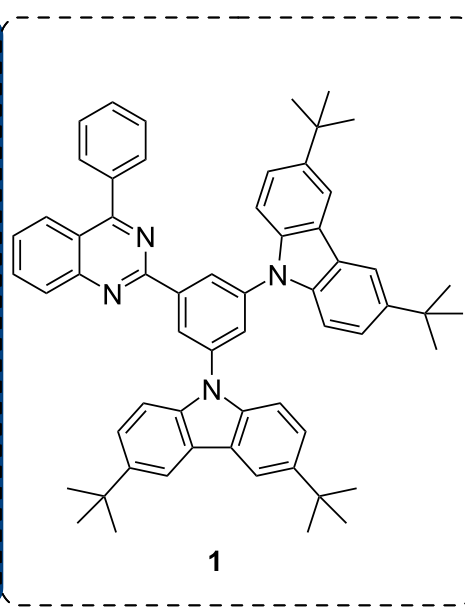

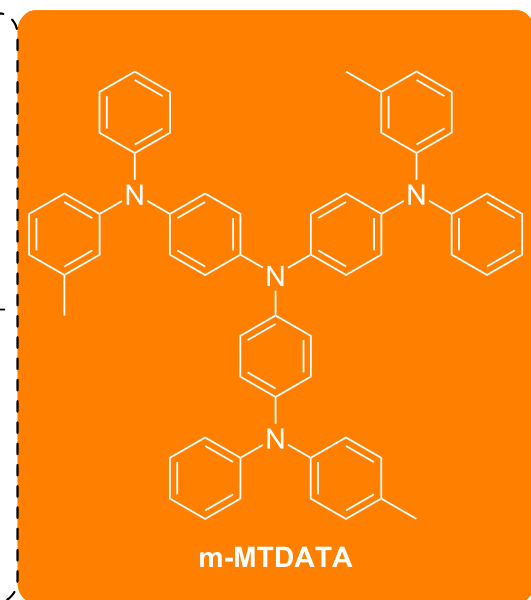

C
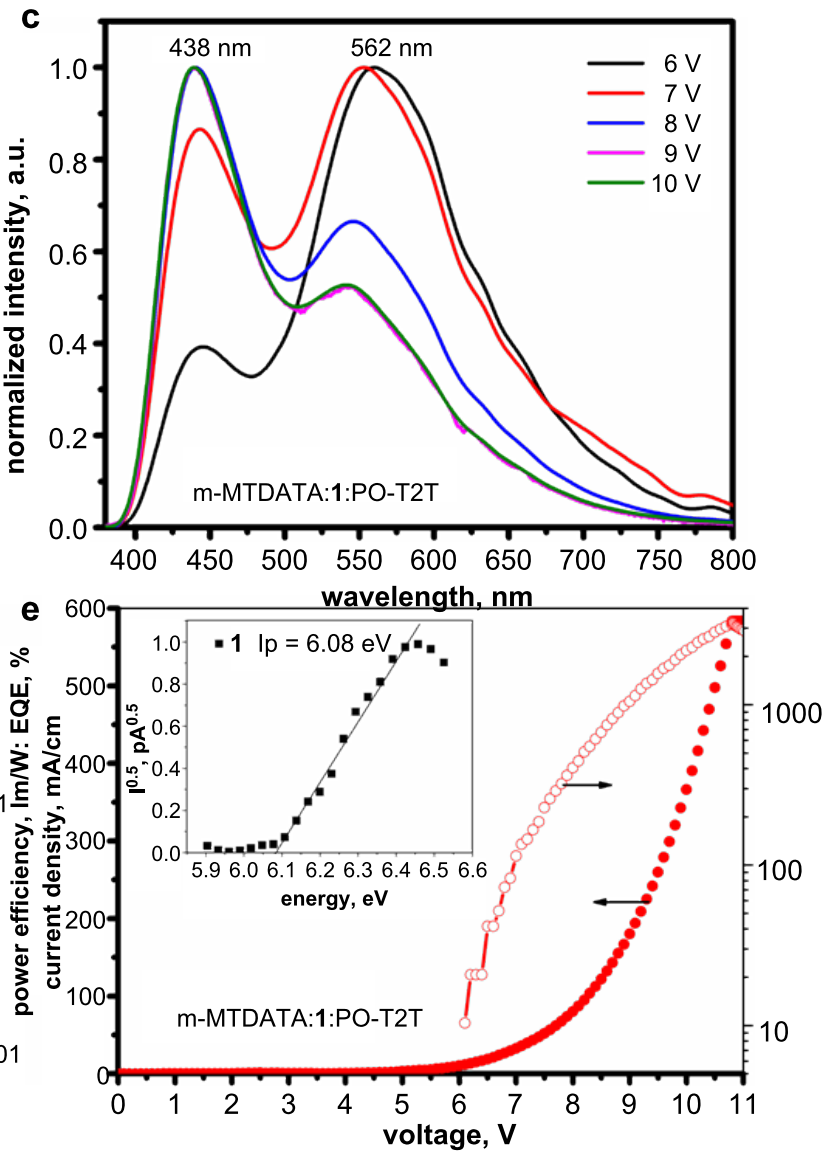

Figure 7: Chemical structures of exciplex-forming materials used, and visualization of white electroluminescence obtained by mixing sky-blue and orange exciplexes (a). PL spectra of the film of 1, of exciplexes m-MTDATA:1/1:PO-T2T and phosphorescence spectrum of the solution of compound 1 in THF at $77 \mathrm{~K}$ (b). Phosphorescence was recorded with the delay of $50 \mathrm{~ms}$ after UV excitation ( $300 \mathrm{~nm}$ ). EL spectra of OLED based on m-MTDATA:1:PO-T2T recorded at different voltages (c). EQE, current and power efficiencies of OLED and equilibrium energy diagram for the lightemitting layer m-MTDATA:1:PO-T2T (d, inset). Current density and brightness versus voltages for the device and photoelectron emission spectrum of the solid sample of compound $\mathbf{1}$ (e, inset). 
in the solid state. Indeed, compound $\mathbf{1}$ formed a sky-blue emitting exciplex $(501 \mathrm{~nm})$ in a solid mixture with the acceptor 2,4,6-tris[3-(diphenylphosphinyl)phenyl]-1,3,5-triazine (POT2T). Moreover, an orange exciplex emission with a PL spectrum peaked at the wavelength of $592 \mathrm{~nm}$ was observed for the solid mixture with the donor 4,4',4"-tris [3-methylphenyl(phenyl)amino]triphenylamine (m-MTDATA) (Figure 7b). The combination of the sky-blue and orange exciplex emissions may result in white electroluminescence (EL). To check this assumption, a non-doped OLED with three light-emitting layers comprising m-MTDATA:1:PO-T2T was fabricated (Figure 7c). The structure of the device was as follows: HAT-CN $(10 \mathrm{~nm}) / \mathrm{NPB}$ $(48 \mathrm{~nm}) / \mathrm{m}$-MTDATA $(16 \mathrm{~nm}) /$ compound $\mathbf{1}(20 \mathrm{~nm}) / \mathrm{PO}-\mathrm{T} 2 \mathrm{~T}$ $(16 \mathrm{~nm}) / \mathrm{TSPO} 1(4 \mathrm{~nm}) / \mathrm{TBPi}(36 \mathrm{~nm})$. In this device architecture, the common hole/electron injecting/transporting/blocking layers hexaazatriphenylenehexacarbonitrile (HAT-CN), $N, N^{\prime}$ $\operatorname{di}\left(1-\right.$ naphthyl)- $N, N^{\prime}$-diphenyl-(1,1'-biphenyl)-4,4'-diamine (NPB), diphenyl[4-(triphenylsilyl)phenyl]phosphine oxide (TSPO1), 2,2',2'-(1,3,5-benzinetriyl)-tris(1-phenyl-1H-benzimidazole) (TPBi), and fluorolithium (LiF) were used. Hole-electron recombination was expected at the two interfaces of m-MTDATA:1 and 1:PO-T2T, resulting in the formation of orange and sky-blue exciplex emissions, respectively. The EL spectrum of the device was characterized by two bands with maximum wavelengths of 438 and $562 \mathrm{~nm}$. The blue shift of the orange exciplex emission of m-MTDATA:1 (the intensity maximum in the PL spectrum was detected at $592 \mathrm{~nm}$ ), could be explained by an overlapping with blue emission. However, the blue shift of the sky-blue emission of the exciplex 1:PO$\mathrm{T} 2 \mathrm{~T}$ could not be explained by the same reason. Most probably, the EL band at $438 \mathrm{~nm}$ was related to the emission of m-MTDATA. Indeed, the high energy barrier at the interface m-MTDATA:1 did not allow a hole reaching the interface 1:PO-T2T (Figure 7d, inset, marked by a crossed arrow) and the maximum EQE value did not exceed $0.5 \%$. The high turn-on voltage of $6.2 \mathrm{~V}$ could be attributed to energy barriers due to the high ionization potential $(6.08 \mathrm{eV})$ of compound 1 (Figure 7e, inset). A relatively high maximum brightness of $3030 \mathrm{~cd} / \mathrm{m}^{2}$ was achieved.

Taking into account the rare detection of versatile exciplexforming properties of compound $\mathbf{1}$ both with a donor and with an acceptor, further investigations are required which could result in a better performance of exciplex-based OLEDs.

\section{Conclusion}

Three quinazoline-based derivatives containing different donor moieties were designed and prepared by a two-step synthesis comprising a facile cyclization and a nucleophilic aromatic substitution reaction. The dimethyldihydroacridine and phenothiazine-containing quinazoline compounds formed molecular glasses with glass-transition temperatures of $123{ }^{\circ} \mathrm{C}$ and $116{ }^{\circ} \mathrm{C}$, respectively. The ionization potentials estimated by cyclic voltammetry of the derivatives were found to be in the range of 5.22-5.87 eV. The 3,6-di-tert-butylcarbazole-substituted quinazoline derivative formed a sky-blue emitting exciplex with the acceptor 2,4,6-tris[3-(diphenylphosphinyl)phenyl]-1,3,5-triazine as well as an orange emitting exciplex with the donor 4,4',4"-tris[3-methylphenyl(phenyl)amino]triphenylamine. A white OLED was fabricated based on the versatile exciplex-forming systems with a relatively high maximum brightness of $3030 \mathrm{~cd} / \mathrm{m}^{2}$ and an EQE of $0.5 \%$.

\section{Experimental Instrumentation}

${ }^{1} \mathrm{H}$ NMR and ${ }^{13} \mathrm{C}$ NMR spectra were recorded with a Bruker Avance III apparatus (400 and $101 \mathrm{MHz}$ ). The samples were prepared by dissolving ca. $20 \mathrm{mg}$ of the material in $1 \mathrm{~mL}$ of deuterated chloroform $\left(\mathrm{CDCl}_{3}\right)$ or dimethylsulfoxide (DMSO- $d_{6}$ ). ${ }^{1} \mathrm{H}$ nuclei were excited by using the frequency of $400 \mathrm{MHz} .{ }^{13} \mathrm{C}$ nuclei were excited by using the frequency of $101 \mathrm{MHz}$. The data are presented as chemical shifts ( $\delta$ ) in ppm (in parentheses: multiplicity, coupling constant, and integration). IR spectra were recorded with a Vertex 70 Bruker spectrometer equipped with an ATR attachment with a diamond crystal over frequencies of $600-3500 \mathrm{~cm}^{-1}$ with a resolution of $5 \mathrm{~cm}^{-1}$ over 32 scans. The IR spectra were presented as a function of transparency $(\mathrm{T})$ expressed in percent (\%) against the wavenumber (v) expressed in $\mathrm{cm}^{-1}$. Elemental analysis was performed with an Exeter Analytical CE-440 elemental analyzer. Mass spectra were obtained with a Waters ZQ 2000 mass spectrometer. The introduction of the sample into the ion source occurred by coupling a gas chromatograph and a highpressure liquid chromatograph. The samples were prepared as dilute solutions of the compounds and were ionized by using electrospray ionization. The mass spectra are presented as an abundance of the ion versus the mass-to-charge ratio $(\mathrm{m} / \mathrm{z})$. Melting points of the compounds were determined with an Electrothermal MEL-TEMP apparatus. Absorption spectra of dilute solutions $\left(10^{-4}-10^{-5} \mathrm{~mol} / \mathrm{L}\right)$ and thin films of the synthesized compounds were recorded with a Perkin Elmer Lambda 25 spectrophotometer. Fluorescence and phosphorescence spectra of thin films and dilute solutions $\left(10^{-4}-10^{-5} \mathrm{~mol} / \mathrm{L}\right)$ of the compounds were recorded at room $(295 \mathrm{~K})$ and low $(77 \mathrm{~K})$ temperatures with a luminescence spectrometer Edinburgh Instruments FLS980. Photoluminescence quantum yields (PLQY) of the solutions and thin films of the materials were measured using an integrating sphere. Phosphorescence spectra were recorded at $77 \mathrm{~K}$. Differential scanning calorimetry (DSC) measurements were carried out using a TA Instruments Q2000 thermosystem. The samples were examined at a heating/cooling rate of $10{ }^{\circ} \mathrm{C} / \mathrm{min}$ under a nitrogen atmosphere. 
Thermogravimetric analysis (TGA) was performed with a TA Instruments Q50 analyzer. The heating rate was $20{ }^{\circ} \mathrm{C} / \mathrm{min}$ under nitrogen atmosphere. Cyclic voltammetry measurements were performed by using a glassy carbon working electrode (a disk with the diameter of $2 \mathrm{~mm}$ ) in a threeelectrode cell with an Autolab Type potentiostat-galvanostat. The measurements were carried out for the solutions in dry dichloromethane containing $0.1 \mathrm{M}$ tetrabutylammonium hexafluorophosphate at $25^{\circ} \mathrm{C}$; the scan rate was $50 \mathrm{mV} / \mathrm{s}$ while the sample concentration was $10^{-3} \mathrm{M}$. The potentials were measured against silver as a reference electrode. A platinum wire was used as a counter electrode. The potentials were calibrated against the standard ferrocene/ferrocenium $\left(\mathrm{Fc} / \mathrm{Fc}^{+}\right)$ redox system [24].

The ground-state geometries were optimized by using the B3LYP (Becke three parameters hybrid functional with Lee-Yang-Perdew correlation) [25] functional at the $6-31 \mathrm{G}(\mathrm{d}, \mathrm{p})$ level of theory in vacuum with the Gaussian software [26].

Firstly, the equilibrium conformer search at the ground state was performed by using the MMFF (molecular mechanics force fields) method, and this geometry was used for further optimization. The vertical singlet and triplet energy values were calculated by using the energy values at the corresponding excitedstate geometry.

The time-dependent DFT (TD-DFT) calculations were carried out with the Gaussian 16 software package and molecular orbitals were visualized by using Gaussview.

Photoelectron emission spectroscopy measurement was performed according to the procedure reported in literature [27] OLED fabrication and characterization was carried out according to the procedure reported earlier [28].

\section{Materials}

2-Aminobenzophenone, 3,5-difluorobenzaldehyde, ammonium acetate, phenothiazine, sodium hydride, sodium sulfate, tert-butyl chloride, zinc chloride (purchased from Aldrich), $9 H$-carbazole, copper(II) chloride (purchased from Reakhim), and 2,7-di-tert-butyl-9,9-dimethyl-9,10-dihydroacridine (purchased from Center for Physical Sciences and Technology) were used as received. Thin-layer chromatography was performed using TLC plates covered with silica gel matrix on aluminum backing (purchased from Aldrich).

3,6-Di-tert-butylcarbazole and 3,7-di-tert-butylphenothiazine were synthesized according to the procedures reported in literature [29].
2-(3,5-Difluorophenyl)-4-phenylquinazoline (Q1) was synthesized according to the procedure reported in literature [14]. A mixture of 2-aminobenzophenone (1.1 g, $5.6 \mathrm{mmol})$, ammonium acetate $(1.3 \mathrm{~g}, 16.9 \mathrm{mmol}), 3,5$-difluorobenzaldehyde $(0.8 \mathrm{~g}$, $5.6 \mathrm{mmol})$, and $\mathrm{CuCl}_{2}(1.5 \mathrm{~g}, 11.2 \mathrm{mmol})$ in $10 \mathrm{~cm}^{3}$ isopropanol was refluxed for $24 \mathrm{~h}$. The progress of the reaction was periodically monitored by thin-layer chromatography. After completion of the reaction, water was added to the mixture until precipitation appeared. The precipitate was collected by filtration and washed with plenty of water to remove excess $\mathrm{CuCl}_{2}, \mathrm{NH}_{4} \mathrm{OAc}$, and reduced copper salt. Compound Q1 (1.4 g, 78\%) was obtained as yellowish crystals. ${ }^{1} \mathrm{H}$ NMR $\left(400 \mathrm{MHz}, \mathrm{CDCl}_{3}\right) \delta$ 8.28-8.22 (m, 2H), $8.16(\mathrm{~d}, J=9.1 \mathrm{~Hz}, 2 \mathrm{H}), 7.96-7.84(\mathrm{~m}, 3 \mathrm{H})$, 7.61 (dd, $J=9.5,6.6 \mathrm{~Hz}, 4 \mathrm{H}), 6.94$ (tt, $J=8.6,2.4 \mathrm{~Hz}, 1 \mathrm{H}$ ); ${ }^{13} \mathrm{C} \mathrm{NMR}\left(101 \mathrm{MHz}, \mathrm{CDCl}_{3}\right) \delta 165.01,161.01,156.01,149.40$, 134.00, 133.90, 133.10, 129.24, 128.8, 128.66, 127.76, 127.4, 127.14, 104.70; ATR-IR (solid state on ATR, $\mathrm{cm}^{-1}$ ): 3098 (Ar C-H), 2904 (Alk C-H), 1559, 1371 (Ar C-N), 1110 (Alk C-F); anal. calcd for $\mathrm{C}_{20} \mathrm{H}_{12} \mathrm{~F}_{2} \mathrm{~N}_{2}$ : C, 75.46; H, 3.80; F, 11.94; N, 8.80; found: $\mathrm{C}, 75.41 ; \mathrm{H}, 3.75 ; \mathrm{F}, 11.99 ; \mathrm{N}, 8.85 \%$; exact mass $318.10 \mathrm{~g} / \mathrm{mol}$; MS $(\mathrm{m} / \mathrm{z}): 319[\mathrm{M}+\mathrm{H}]^{+}$.

\section{General procedure for the synthesis of compounds 1-3}

The target compounds 1-3 were synthesized through nucleophilic substitution reactions between quinazoline derivative Q1 and the respective donor compound in the presence of sodium hydride in dry dimethylformamide (DMF). The reaction mixtures were refluxed for $24 \mathrm{~h}$. After completion of the reactions, the reaction mixtures were poured into water, extracted with chloroform $(3 \times 50 \mathrm{~mL})$ and dried over sodium sulfate. The compounds were purified by column chromatography using hexane as eluent and recrystallized from acetone.

9,9'-(5-(4-Phenylquinazolin-2-yl)-1,3-phenylene)bis(3,6-ditert-butyl-9H-carbazole) (1): Quinazoline derivative (Q1, $0.25 \mathrm{~g}, 0.79 \mathrm{mmol}), 3,6$-di-tert-butylcarbazole $(0.48 \mathrm{~g}$, $1.7 \mathrm{mmol})$ and sodium hydride $(0.50 \mathrm{~g}, 1.6 \mathrm{mmol})$ in dry dimethylformamide (DMF) were used for the nucleophilic substitution reaction. The title compound was obtained as yellowish crystals in a yield of $0.25 \mathrm{~g}, 37 \% ; T_{\mathrm{m}}=181{ }^{\circ} \mathrm{C}$ (DSC); ${ }^{1} \mathrm{H}$ NMR (400 MHz, $\left.\mathrm{CDCl}_{3}\right) \delta 8.18(\mathrm{~d}, J=7.1 \mathrm{~Hz}, 2 \mathrm{H})$, 8.09 (t, $J=7.5 \mathrm{~Hz}, 2 \mathrm{H}), 8.00(\mathrm{~s}, 4 \mathrm{H}), 7.87-7.69(\mathrm{~m}, 4 \mathrm{H}), 7.53$ $(\mathrm{dd}, J=9.5,6.3 \mathrm{~Hz}, 3 \mathrm{H}), 7.38(\mathrm{~d}, J=8.5 \mathrm{~Hz}, 4 \mathrm{H}), 7.25(\mathrm{~d}, J=$ $8.5 \mathrm{~Hz}, 4 \mathrm{H}), 6.86(\mathrm{t}, J=8.5 \mathrm{~Hz}, 1 \mathrm{H}), 1.37(\mathrm{~s}, 36 \mathrm{H}) ;{ }^{13} \mathrm{C} \mathrm{NMR}$ $\left(101 \mathrm{MHz}, \mathrm{CDCl}_{3}\right) \delta 165.01,161.01,156.01,149.40,144.90$, $142.40,142.24,138.05,133.95,130.22,129.24,128.66,127.76$, 127.14, 123.43, 116.19, 110.00, 77.35, 77.03, 76.72, 34.71, 32.05; ATR-IR (solid state on ATR, $\mathrm{cm}^{-1}$ ): 3061 (Ar C-H), 2969 (Alk C-H), ) 1490, 1361, 1262 (Ar C-N), 980, 880 (Alk C-H); anal. calcd for $\mathrm{C}_{60} \mathrm{H}_{60} \mathrm{~N}_{4}$ : C, 86.08; H, 7.23; N, 6.69; 
found: C, $86.03 ; \mathrm{H}, 7.20 ; \mathrm{N}, 6.68 \%$; exact mass $836.48 \mathrm{~g} / \mathrm{mol}$; MS $(\mathrm{m} / \mathrm{z}): 836\left[\mathrm{M}^{+}\right]$.

9,9'-(5-(4-Phenylquinazolin-2-yl)-1,3-phenylene)bis(2,7-ditert-butyl-9,9-dimethyl-9,10-dihydroacridine) (2): Quinazoline derivative (Q1, $0.22 \mathrm{~g}, 0.69 \mathrm{mmol})$, 2,7-di-tert-butyl-9,9dimethyl-9,10-dihydroacridine $(0.58 \mathrm{~g}, 2.79 \mathrm{mmol})$ and sodium hydride $(0.50 \mathrm{~g}, 1.6 \mathrm{mmol})$ in dry dimethylformamide (DMF) were used for the nucleophilic substitution reaction. The title compound was obtained as yellowish crystals in a yield of $0.10 \mathrm{~g}, 21 \% ; T_{\mathrm{m}}=233{ }^{\circ} \mathrm{C} ;{ }^{1} \mathrm{H}$ NMR $\left(400 \mathrm{MHz}, \mathrm{CDCl}_{3}\right) \delta 8.93$ $(\mathrm{s}, 2 \mathrm{H}), 8.11(\mathrm{~s}, 2 \mathrm{H}), 7.89-7.84(\mathrm{~s}, 4 \mathrm{H}), 7.56(\mathrm{~s}, 4 \mathrm{H}), 7.48(\mathrm{~d}$, $J=7.6 \mathrm{~Hz}, 3 \mathrm{H}), 7.04(\mathrm{~s}, 4 \mathrm{H}), 6.95(\mathrm{~s}, 3 \mathrm{H}), 6.57$ (d, $J=8.1 \mathrm{~Hz}$, $2 \mathrm{H}), 1.72(\mathrm{~s}, 48 \mathrm{H}) ;{ }^{13} \mathrm{C} \mathrm{NMR}\left(101 \mathrm{MHz}, \mathrm{CDCl}_{3}\right) \delta 165.01$, 161.01, 156.01, 149.40, 144.90, 142.40, 134.00, 133.90, 133.10, $132.50,129.24,128.8,128.66,127.76,127.4,127.14,122.8$, 123.50, 77.35, 77.03, 76.72, 34.71, 32.05, 31.0; ATR-IR (solid state on ATR, $\mathrm{cm}^{-1}$ ): 3055 (Ar C-H), 2972 (Alk C-H),) 1495, 1359, 1262 (Ar C-N), 974, 882 (Alk C-H); anal. calcd for compound $\mathrm{C}_{66} \mathrm{H}_{72} \mathrm{~N}_{4}$ : C, 86.04; $\mathrm{H}, 7.88 ; \mathrm{N}, 6.08$; found: C, 85.99; $\mathrm{H}, 7.91 ; \mathrm{N}, 6.10 \%$; exact mass $920.56 \mathrm{~g} / \mathrm{mol}$; MS $(\mathrm{m} / \mathrm{z}): 922[\mathrm{M}$ $+\mathrm{H}]^{+}$.

9,9'-(5-(4-Phenylquinazolin-2-yl)-1,3-phenylene)bis(3,7-ditert-butylphenothiazine) (3): Quinazoline derivative (Q1, $0.30 \mathrm{~g}, 0.9 \mathrm{mmol}), 3,7$-di-tert-butylphenothiazine $(0.73 \mathrm{~g}$, $1.2 \mathrm{mmol})$ and sodium hydride $(0.5 \mathrm{~g}, 1.6 \mathrm{mmol})$ in dry dimethylformamide (DMF) were used for the nucleophilic substitution reaction. The title compound was obtained as yellowish crystals in a yield of $0.194 \mathrm{~g}, 23 \% ; T_{\mathrm{m}}=144{ }^{\circ} \mathrm{C}$; ${ }^{1} \mathrm{H}$ NMR (400 MHz, DMSO) $\delta 8.39$ (s, 1H), 7.71 (s, 2H), 7.13 $(\mathrm{d}, J=2.1 \mathrm{~Hz}, 3 \mathrm{H}), 7.02-6.88(\mathrm{~m}, 11 \mathrm{H}), 6.75(\mathrm{~d}, J=8.3 \mathrm{~Hz}$, $2 \mathrm{H}), 6.62(\mathrm{~d}, J=8.3 \mathrm{~Hz}, 2 \mathrm{H}), 6.02(\mathrm{~d}, J=7.5 \mathrm{~Hz}, 3 \mathrm{H})$, 1.27-1.09 (m, 36H); ${ }^{13} \mathrm{C}$ NMR (101 MHz, DMSO) $\delta 165.01$, 161.01, 156.01, 149.40, 144.90, 140.80, 138.05, 133.95, 130.22, 129.24, 128.66, 127.76, 124.50, 122.90, 121.60, 115.51, 115.0, 77.35 (s), 77.35, 77.03, 76.72, 34.71, 32.05; ATR-IR (solid state on ATR, cm $\left.{ }^{-1}\right)$ : 3069 (Ar C-H), 2971 (Alk C-H), 1265 (Ar $\mathrm{C}-\mathrm{N}$ ); anal. calcd for $\mathrm{C}_{60} \mathrm{H}_{60} \mathrm{~N}_{4} \mathrm{~S}_{2}$ : C, 79.96; H, 6.71; N, 6.22; S, 7.11; found: C, 79.91; H, 6.66; N, 6.27; S, 7.16\%; exact mass $900.43 \mathrm{~g} / \mathrm{mol} ; \mathrm{MS}(\mathrm{m} / \mathrm{z}): 901[\mathrm{M}+\mathrm{H}]^{+}$.

\section{Funding}

This project received funding from the European Union's Horizon 2020 research and innovation programme under the Marie Skłodowska-Curie grant agreement No 823720

\section{ORCID ${ }^{\circledR}$ iDs}

Rasa Keruckiene - https://orcid.org/0000-0002-9809-5815 Dmytro Volyniuk - https://orcid.org/0000-0003-3526-2679

\section{References}

1. Hung, W.-Y.; Chiang, P.-Y.; Lin, S.-W.; Tang, W.-C.; Chen, Y.-T.; Liu, S.-H.; Chou, P.-T.; Hung, Y.-T.; Wong, K.-T. ACS Appl. Mater. Interfaces 2016, 8, 4811-4818. doi:10.1021/acsami.5b11895

2. Rodrigues, A. C. B.; Pina, J.; Dong, W.; Forster, M.; Scherf, U.; Seixas de Melo, J. S. Macromolecules 2018, 51, 8501-8512. doi:10.1021/acs.macromol.8b01758

3. Konidena, R. K.; Lee, K. H.; Lee, J. Y. Chem. - Asian J. 2019, 14, 313-321. doi:10.1002/asia.201801627

4. Keruckiene, R.; Keruckas, J.; Jatautiene, E.; Simokaitiene, J.; Volyniuk, D.; Grazulevicius, J. V. J. Photochem. Photobiol., A 2018, 359, 157-163. doi:10.1016/j.jphotochem.2018.04.010

5. Held, F. E.; Guryev, A. A.; Fröhlich, T.; Hampel, F.; Kahnt, A.; Hutterer, C.; Steingruber, M.; Bahsi, H.; von Bojničić-Kninski, C.; Mattes, D. S.; Foertsch, T. C.; Nesterov-Mueller, A.; Marschall, M.; Tsogoeva, S. B. Nat. Commun. 2017, 8, 15071. doi:10.1038/ncomms15071

6. Li, B.; Wang, Z.; Su, S.-J.; Guo, F.; Cao, Y.; Zhang, Y. Adv. Opt. Mater. 2019, 7, 1801496. doi:10.1002/adom.201801496

7. Zhang, Z.; Xie, J.; Wang, H.; Shen, B.; Zhang, J.; Hao, J.; Cao, J.; Wang, Z. Dyes Pigm. 2016, 125, 299-308. doi:10.1016/j.dyepig.2015.10.042

8. Kang, S. K.; Woo, J.; Lee, S. E.; Kim, Y. K.; Yoon, S. S. Mol. Cryst. Liq. Cryst. 2019, 679, 8-15. doi:10.1080/15421406.2019.1597540

9. Liu, D.; Zhang, Z.; Zhang, H.; Wang, Y. Chem. Commun. 2013, 49, 10001-10003. doi:10.1039/c3cc45991h

10. Sych, G.; Simokaitiene, J.; Bezvikonnyi, O.; Tsiko, U.; Volyniuk, D.; Gudeika, D.; Grazulevicius, J. V. J. Phys. Chem. C 2018, 122, 14827-14837. doi:10.1021/acs.jpcc.8b03895

11. Popp, L.; Scholz, R.; Kleine, P.; Lygaitis, R.; Lenk, S.; Reineke, S. Org. Electron. 2019, 75, 105365. doi:10.1016/j.orgel.2019.07.023

12. Komatsu, R.; Sasabe, H.; Seino, Y.; Nakao, K.; Kido, J. J. Mater. Chem. C 2016, 4, 2274-2278. doi:10.1039/c5tc04057d

13. Nobuyasu, R. S.; Ward, J. S.; Gibson, J.; Laidlaw, B. A.; Ren, Z.; Data, P.; Batsanov, A. S.; Penfold, T. J.; Bryce, M. R.; Dias, F. B. J. Mater. Chem. C 2019, 7, 6672-6684. doi:10.1039/c9tc00720b

14. Saad, S. M.; Khan, K. M.; Perveen, S.; Voelter, W.; Taha, M. Monatsh. Chem. 2015, 146, 1877-1880. doi:10.1007/s00706-015-1460-5

15. Thokala, S.; Singh, S. P. ACS Omega 2020, 5, 5608-5619. doi:10.1021/acsomega.0c00065

16. Tu, C.; Liang, W. Org. Electron. 2018, 57, 74-81. doi:10.1016/j.orgel.2018.02.035

17. Cardona, C. M.; Li, W.; Kaifer, A. E.; Stockdale, D.; Bazan, G. C Adv. Mater. (Weinheim, Ger.) 2011, 23, 2367-2371. doi:10.1002/adma.201004554

18. Rybakiewicz, R.; Gawrys, P.; Tsikritzis, D.; Emmanouil, K.; Kennou, S.; Zagorska, M.; Pron, A. Electrochim. Acta 2013, 96, 13-17. doi:10.1016/j.electacta.2013.02.041

19. Yang, J.; Zhen, X.; Wang, B.; Gao, X.; Ren, Z.; Wang, J.; Xie, Y.; Li, J.; Peng, Q.; Pu, K.; Li, Z. Nat. Commun. 2018, 9, 840. doi:10.1038/s41467-018-03236-6

20. Rudnick, A. A.; Bagnich, S.; Wagner, D.; Athanasopoulos, S.; Strohriegl, P.; Köhler, A. J. Chem. Phys. 2016, 144, 214906. doi:10.1063/1.4953102 
21. Reichardt, C.; Welton, T. Solvents and Solvent Effects in Organic Chemistry, 4th ed.; Wiley-VCH: Weinheim, Germany, 2010. doi:10.1002/9783527632220

22. Karpicz, R.; Puzinas, S.; Krotkus, S.; Kazlauskas, K.; Jursenas, S.; Grazulevicius, J. V.; Grigalevicius, S.; Gulbinas, V. J. Chem. Phys. 2011, 134, 204508. doi:10.1063/1.3594047

23. Reghu, R. R.; Grazulevicius, J. V.; Simokaitiene, J.; Miasojedovas, A.; Kazlauskas, K.; Jursenas, S.; Data, P.; Karon, K.; Lapkowski, M.; Gaidelis, V.; Jankauskas, V. J. Phys. Chem. C 2012, 116, 15878-15887. doi:10.1021/jp3019952

24. Gritzner, G.; Kuta, J. Pure Appl. Chem. 1984, 56, 461-466. doi:10.1351/pac198456040461

25. Becke, A. D. Phys. Rev. A 1988, 38, 3098-3100. doi:10.1103/physreva.38.3098

26. Gaussian 16, Revision B.01; Gaussian, Inc.: Wallingford, CT, 2016

27. Turkovic, V.; Prete, M.; Bregnhøj, M.; Inasaridze, L.; Volyniuk, D.; Obrezkov, F. A.; Grazulevicius, J. V.; Engmann, S.; Rubahn, H.-G.; Troshin, P. A.; Ogilby, P. R.; Madsen, M. ACS Appl. Mater. Interfaces 2019, 11, 41570-41579. doi:10.1021/acsami.9b13085

28. Guzauskas, M.; Volyniuk, D.; Tomkeviciene, A.; Pidluzhna, A.; Lazauskas, A.; Grazulevicius, J. V. J. Mater. Chem. C 2019, 7, 25-32. doi:10.1039/c8tc04708a

29. Kormos, A.; Móczár, I.; Sveiczer, A.; Baranyai, P.; Párkányi, L.; Tóth, K.; Huszthy, P. Tetrahedron 2012, 68, 7063-7069. doi:10.1016/j.tet.2012.06.070

\section{License and Terms}

This is an Open Access article under the terms of the Creative Commons Attribution License (http://creativecommons.org/licenses/by/4.0). Please note that the reuse, redistribution and reproduction in particular requires that the authors and source are credited.

The license is subject to the Beilstein Journal of Organic Chemistry terms and conditions: (https://www.beilstein-journals.org/bjoc)

The definitive version of this article is the electronic one which can be found at: $\underline{\text { doi:10.3762/bjoc.16.101 }}$ 